\title{
Tecnologias ambientais: em busca de um significado*
}

\author{
Charbel José Chiappetta Jabbour**
}

Sumário: 1. Introdução; 2. Diversidade terminológica e conceitual; 3. Tipologia das tecnologias ambientais; 4. Mecanismos de desenvolvimento e difusão; 5. Considerações finais.

Summary: 1. Introduction; 2. Diversity of terms and concepts; 3. Environmental technology taxonomy; 4. Development and dissemination mechanisms; 5. Final remarks.

Palavras-chave: tecnologia; meio ambiente; tecnologia ambiental.

KEY-WORDs: technology; environment; environmental technology.

Este artigo busca um significado mais preciso e completo para um termo cuja adoção revela-se crescente nos fóruns acadêmicos e empresariais: tecnologia ambiental. De fato, o desenvolvimento, a adoção e a difusão de tecnologias ambientais implicam o envolvimento de diversos agentes, instituições e setores sociais, que requerem um entendimento comum e devidamente completo para o significado de tecnologia ambiental. Entretanto, as propostas conceituais mais atuais são tímidas diante do desafio de se buscar um significado mais claro para o termo. Assim, este artigo explora a tipologia do termo e identifica seu processo de desenvolvimento e difusão, fornecendo um significado mais completo de tecnologia ambiental.

\footnotetext{
* Artigo recebido em nov. 2007 e aceito em abr. 2009. Este artigo foi apresentado durante o XXXI Enanpad, realizado no Rio de Janeiro, entre 23 e 26 de setembro de 2007. O autor agradece à Fapesp pelos recursos concedidos no âmbito do Processo no 06/53549-6, que viabilizaram a realização da pesquisa.

** Professor doutor da Universidade de São Paulo, Faculdade de Economia, Administração e Contabilidade de Ribeirão Preto (USP/FEA-RP). Doutor em engenharia de produção pela Escola de Engenharia de São Carlos da Universidade de São Paulo (EESC/USP). É docente dos cursos de Mestrado e Doutorado em Administração de Organizações da USP/FEA-RP e colaborador no curso de Mestrado em Engenharia de Produção (Unesp-Bauru). Endereço: Universidade de São Paulo/FEA-RP, Depto. de Administração, Av. Bandeirantes, 3900 - CEP 14900-040, Ribeirão Preto, SP, Brasil. E-mail: charbel@usp.br.
} 


\section{Environmental technologies: in search of a meaning}

This article searches for a more complete meaning for an expression which has been more and more adopted by academic and managerial forums: environmental technology. The development, adoption and diffusion of environmental technologies require that social agents, institutions and social sectors have a common and proper understanding of the meaning of environmental technology. However, the state of the art conceptual proposals are unable to answer the challenge of finding a clear definition of the term. This article explores the term's taxonomy and identifies it's development and dissemination process, giving a fuller meaning for environmental technology.

\section{Introdução}

Na esteira dos prognósticos sobre catástrofes climáticas futuras e a ascensão de imperativos ambientais desafiadores para a humanidade, adquirem maiores proporções e adeptos os argumentos que atribuem grande relevância às necessidades de transformações tecnológicas, que condicionariam, por conseguinte, as melhorias nas atuais condições ambientais. O estágio seguinte desse argumento é aceitar como válida a afirmação de que são "os avanços no campo da ciência e tecnologia que vão possibilitar o surgimento de novos produtos e processos que aumentem constantemente a eficiência dos recursos produtivos e reduzam os níveis de emissão de poluentes" (Barbieri, 2004:75).

Essas transformações tecnológicas implicam interação de dois conceitos cuja história é dicotômica, quando não conflituosa. São mencionados os termos "tecnologia" e "ambiente natural" que, num passado recente, eram tomados como mutuamente excludentes, pois se acreditava que o desenvolvimento de um associava-se ao entrave do outro. Essas considerações levaram Hall e Clark (2003) a afirmarem que, geralmente, a união dos conceitos "tecnologia" e "ambiente natural" possui importância crítica, a despeito de fomentar vicissitudes terminológicas que acompanham confusão conceitual.

O argumento defendido por Hall e Clark (2003) pode ser verificado durante a revisão de algumas das principais obras, constantes no quadro 1 , que revelam tendências no estado-da-arte desse campo de pesquisa. Foram identificados dois tipos de imprecisões sobre a incorporação da dimensão ambiental no contexto tecnológico. O primeiro deles concerne à pluralidade, e consequente imprecisão, de termos referentes a esse processo. Por exemplo, identificou-se mais de uma dezena de nomenclaturas para mencionar as tecnologias que incorporam aspectos ambientais em seu âmbito. Aqui, o termo tecnologia ambiental será assumido como nomenclatura para essa categoria tecnológica. Justificativas para tal escolha serão dadas no decorrer da pesquisa, mas adian- 
ta-se que tais tecnologias, por seu enfoque na redução de impactos ambientais, são adjetivadas pela palavra que representa o objetivo primordial de sua gênese/aplicação/transferência, conhecidas como tecnologias ambientais.

A segunda imprecisão que se observa vincula-se ao entendimento dos pesquisadores sobre o que vem a ser uma tecnologia ambiental. Em algumas pesquisas (Layrargues, 2000), os autores delimitam um escopo analítico que apenas objetiva criticar as tecnologias ambientais dentro de uma perspectiva funcional na sociedade capitalista. Em outras (Vandermerwe e Oliff, 1990), verificam-se definições que contribuem pouco para a edificação de um significado. Por fim, cabe ressaltar pesquisas que abordam a temática das tecnologias ambientais, mas que se furtam a assumir um posicionamento conceitual sobre o tema (Cunha-e-Sá e Reis, 2007).

Como observa Kuehr (2007), essa dupla imprecisão contribui para que os agentes envolvidos no processo de desenvolvimento e difusão de tecnologias ambientais tendam a estabelecer um diálogo desconexo. Além disso, as vicissitudes ora apresentadas dificultam uma compreensão mais lúcida das ações e transformações que podem ser empreendidas pelos dirigentes organizacionais em atividades relacionadas ao desenvolvimento, adoção e transferência de tecnologias ambientais.

Dessa forma, declara-se como motivação para a condução deste artigo a seguinte inquietação: pode-se construir um significado mais completo para o termo tecnologia ambiental, por meio da sistematização conceitual, exploração tipológica e verificação de seu processo de difusão? Aderente a essa proposta, despontam como objetivos:

v sistematizar, no contexto de uma releitura crítica, os principais conceitos de tecnologia ambiental divulgados pela literatura pertinente, representativa do estado-da-arte da temática;

- investigar as propostas de tipologias das tecnologias ambientais, a fim de se avançar na categorização e operacionalização desse conceito;

- identificar as principais considerações sobre o processo, os entraves e as possibilidades do desenvolvimento e da consequente difusão de tecnologias ambientais;

- buscar um significado para o termo sob análise, construindo-o com base nos pressupostos desenvolvidos durante a consecução dos objetivos citados.

- Para tanto, este artigo apresenta, na seção 2, uma revisão dos principais conceitos de tecnologia ambiental comunicados pelos pesquisadores da área, depois de empreendida uma revisão teórica de amplitude nacional e 
internacional (quadro 1). Em seguida, são apresentadas as tipologias das tecnologias ambientais, em que se avança no sentido de fornecer um desdobramento operacional e categorizado do termo (seção 3). A seção 4 discorre sobre as principais características do processo de desenvolvimento e difusão das tecnologias ambientais. Em cada uma dessas seções, são destacados os aspectos conceituais mais relevantes sobre o objeto em análise, que são resgatados, de uma forma cabal, na seção 5 , a fim de se oferecer uma abordagem mais completa sobre o significado de tecnologia ambiental.

\section{Diversidade terminológica e conceitual}

Observa-se uma grande diversidade de nomenclaturas para se reportar às tecnologias ambientais. Tanto na literatura nacional, quanto na internacional, há uma pluralidade de termos que se relaciona à consideração de aspectos ambientais no desenvolvimento tecnológico. A diversidade terminológica pode ser observada a seguir:

v tecnologias ambientais alternativas (Kolar, 2000);

v tecnologias ambientalmente interessantes (Unep, 2002);

v tecnologias verdes (Kivimaa e Mickwitz, 2006);

v tecnologias ambientalmente amigáveis (Barbieri, 2004);

$\checkmark$ ecotecnologias (Smith, 2001);

v inovações tecnológicas ambientalmente saudáveis (Barbieri, 1997);

$\checkmark$ tecnologias limpas (Mazon, 1992);

v tecnologias mais limpas (ONU, 1992);

v tecnologias ambientalmente sensíveis (Mazon, 1992);

v tecnologias ambientalmente avançadas (Olson, 1991);

v tecnologias naturais avançadas (Olson, 1991);

v soluções ambientalmente amigáveis (Martinsons e colaboradores, 1997);

v tecnologias ambientalmente benéficas (Jaffe, Newell e Stavins, 2005);

v tecnologias mais verdes (Conway e Steward, 1998);

v tecnologias não agressivas ao meio ambiente (Donaire, 1999);

v tecnologias ambientalmente sustentáveis (Hall e Vrendenburg, 2003). 
Essa pluralidade terminológica carrega em seu bojo uma perceptível imprecisão conceitual, o que conduz ao desenvolvimento de pesquisas em que se discorre sobre aspectos relacionados às tecnologias ambientais furtando-se a um posicionamento conceitual. Tal exemplo torna-se mais explícito quando se investiga os trabalhos realizados por Lanjouw e Mody (1996) e em Cunhae-Sá e Reis (2007), nos quais não se delimita, com a devida precisão, o entendimento desses autores sobre o termo tecnologia ambiental. Em outras pesquisas (Layrargues, 2000) verificou-se uma pujante crítica à adoção de tecnologias ambientais no contexto da sociedade capitalista, mas não se observou um arcabouço conceitual sobre essa categoria tecnológica, isto é, não se avançou em busca de um significado mais preciso.

Quando conceituado, verificou-se que o termo é tratado como tendo fronteiras amplas e difusas. Essa observação adquire maior verdade ao se analisar o argumento de que

novas indústrias de porte relacionadas ao reprojeto de processos de manufatura, à reutilização de materiais residuais, à eficiência energética, à energia renovável, à agricultura sustentável, ao transporte eficiente, à arquitetura e projetos urbanos ambientalmente sensíveis e uma realidade completamente nova de tecnologia verde está aguardando desenvolvimento.

(Mazon, 1992)

Nesse exemplo não ficam claros quais os limites conceituais atribuídos à tecnologia ambiental, no contexto de uma perspectiva operacional desta, que facilite sua compreensão por estudiosos e dirigentes organizacionais.

Tal argumentação (Mazon, 1992) tende a suscitar algumas dúvidas nos leitores: (a) tecnologias ambientalmente sensíveis são aquelas que se sensibilizam com as causas ambientais ou aquelas que possuirão um desempenho sofrível e serão substituídas caso a qualidade do ambiente natural tenda a piorar; (b) as tecnologias ambientais serão o foco de novas indústrias, serão abarcadas por indústrias já existentes ou serão desenvolvidas por um processo industrial híbrido, num misto de criação de novas indústrias e transformação de existentes; (c) as tecnologias ambientais podem ser consideradas plenamente sustentáveis?

Consta, na Agenda 21, que "as tecnologias ambientalmente saudáveis protegem o meio ambiente, são menos poluentes, usam todos os recursos de forma mais sustentável, reciclam mais seus resíduos e produtos e tratam os dejetos residuais de uma maneira mais aceitável que as tecnologias que vieram 
substituir" (ONU, 1992). No mesmo documento consta que "as tecnologias ambientalmente saudáveis, no contexto da poluição, são 'tecnologias de processos e produtos' que geram pouco ou nenhum resíduo, para a prevenção da poluição [compreendendo] tecnologias de 'etapa final' para o tratamento da poluição depois que esta foi produzida" (ONU, 1992). Com base nessa proposta de conceituação, pode-se indagar: (a) poderiam as chamadas tecnologias ambientalmente saudáveis gerar impactos ambientais negativos, mesmo durante sua fabricação; (b) quer-se afirmar que o meio ambiente deve se tornar saudável por meio dessa tecnologia, ou que ela em si incorpora o conceito "saudável"?

Navegando por outras propostas conceituais, cabe ressaltar o entendimento das tecnologias ambientais para Jaffe, Newell e Stavins (2005), para os quais essa categoria engloba novas tecnologias que promovem a resolução de problemas ambientais por meio da mitigação dos efeitos de poluentes. Como se percebe, essa definição vincula-se a uma abordagem de controle da poluição - e consequentemente restrita - uma vez que as tecnologias ambientais, para tais pesquisadores, agem sobre os poluentes já gerados. Outra disfunção conceitual é encontrada em Vandermerwe e Oliff (1990), os quais indicam que as tecnologias limpas reduzem os custos de produção por meio de economias em matérias-primas e energia, levando a um aumento da produtividade e, consequentemente, a uma melhoria na competitividade da firma. Assim, tais autores, ao invés de avançarem na construção de um significado para tecnologia ambiental, a definem por meio dos potenciais benefícios econômicos que sua adoção pode gerar para as empresas.

Adicionalmente, Rounds e Cooper (2002) afirmam que tal objeto diz respeito à consideração sistemática dos critérios ambientais durante todo o processo de desenvolvimento de novas tecnologias. Entretanto, a consideração de critérios ambientais no desenvolvimento de novas tecnologias, por mais sistemática que seja, não garante que ao final desse desenvolvimento seja gerada uma tecnologia ambiental. Além disso, pode-se considerar a inserção da dimensão ambiental no contexto de tecnologias já existentes, de maneira incremental.

Para Olson (1991), a dificuldade observada quanto à conceituação de tecnologia ambiental pode ser facilitada por meio da análise dos requisitos que essa modalidade deve atender. Segundo ele, uma tecnologia ambiental requer, concomitantemente: 
- ser, em sua essência, sustentável. Ela será capaz de reduzir os impactos ambientais da tecnologia que substituiu, estando disponibilizada para todos os indivíduos que a requererem, sem esgotar a utilização de determinados recursos para seu desenvolvimento e sem apresentar consequências ambientais críticas;

- estar pautada em energia limpa e inesgotável. À luz de uma metáfora fotossintética, o autor postula que a tecnologia absorva energia inesgotável e limpa, principalmente a energia solar;

v utilizar recursos energéticos e outros recursos de forma eficientemente ótima. Idealmente, as tecnologias ambientais devem se valer de energias limpas e inesgotáveis, processando-as eficientemente e sem perdas energéticas. Adicionalmente, devem transformar outros componentes de input com eficiência máxima;

v possuir capacidade para reciclar e resgatar componentes com eficiência, para que estes sirvam como inputs de um novo ciclo produtivo que se iniciará;

- apresentar grande valor de inteligência artificial agregado. Assim, as tecnologias ambientais serão pautadas em sofisticados sistemas de aquisição, tratamento e interpretação de dados e informações, para fins de monitoramento e escolha das alternativas que resultem em reduzidos impactos ambientais.

A análise dos requisitos propostos por Olson (1991) permite verificar a imprecisão conceitual com que tal autor considera o significado de tecnologia ambiental. O primeiro argumento do autor extrapola os limites funcionais de uma tecnologia ambiental, pois, de fato, não se pode garantir que ela contribua para o ambiente natural ao mesmo passo que gera desenvolvimento econômico e social, apesar dessa proposta ser louvável. O segundo argumento mostra-se falaz, pois, por mais ideal que seja a utilização de fontes renováveis de energia, não se pode afirmar, ainda, que todos os componentes e subsistemas de uma tecnologia ambiental operam ou são obtidos por meio de energia renovável. Por fim, a imprecisão conceitual fica evidente quando o autor afirma que as tecnologias ambientais devem incorporar outras tecnologias avançadas, pois essa tendência mostra-se verídica para o conjunto de categorias tecnológicas que conhecemos e não é exclusiva às tecnologias ambientais. 


\section{Quadro 1 \\ Algumas contribuições de pesquisas realizadas no campo das tecnologias ambientais}

\begin{tabular}{|c|c|c|}
\hline Pesquisa & Principal contribuição & Natureza \\
\hline $\begin{array}{l}\text { Azzone, Bertelè e Noci } \\
\text { (1997) }\end{array}$ & $\begin{array}{l}\text { Propõem e conceituam as estratégias e características } \\
\text { organizacionais para a geração de tecnologias } \\
\text { ambientais sob a forma de processos e produtos }\end{array}$ & Teórica \\
\hline Brío e Junquera (2003) & $\begin{array}{l}\text { Discorrem sobre os desafios para a geração de } \\
\text { tecnologias ambientais nas pequenas empresas }\end{array}$ & Teórico-empírica \\
\hline Chen, Lai e Wen (2006) & $\begin{array}{l}\text { Investigaram a correlação entre desenvolvimento de } \\
\text { tecnologias ambientais em produtos e processos e a } \\
\text { performance competitiva de empresas tailandesas }\end{array}$ & Teórico-empírica \\
\hline $\begin{array}{l}\text { Conway e Steward } \\
\text { (1998) }\end{array}$ & $\begin{array}{l}\text { Identificam as redes e agentes para a geração de } \\
\text { tecnologias ambientais em } 20 \text { casos do Reino Unido e } \\
\text { da Alemanha }\end{array}$ & Teórico-empírica \\
\hline $\begin{array}{l}\text { Green, McMeekin e Irwin } \\
\text { (1994) }\end{array}$ & $\begin{array}{l}\text { Investigam as motivações para a geração de tecnologias } \\
\text { ambientais por empresas do Reino Unido }\end{array}$ & Teórico-empírica \\
\hline Hall e Kerr (2003) & $\begin{array}{l}\text { Analisam a dinâmica da geração de tecnologias } \\
\text { ambientais, sob o ponto de vista incremental e radical }\end{array}$ & Teórica \\
\hline $\begin{array}{l}\text { Hall e Vrendenburg } \\
\text { (2003) }\end{array}$ & $\begin{array}{l}\text { Apresentam os principais desafios para a geração de } \\
\text { tecnologias ambientais }\end{array}$ & Teórico-empírica \\
\hline $\begin{array}{l}\text { Kivimaa e Mickwitz } \\
\text { (2006) }\end{array}$ & $\begin{array}{l}\text { Avaliam o apoio governamental para a geração de } \\
\text { tecnologias ambientais na Finlândia, por meio da } \\
\text { política de ciência e tecnologia (C\&T) }\end{array}$ & Teórico-empírica \\
\hline $\begin{array}{l}\text { Klassen e Whybark } \\
\text { (1999) }\end{array}$ & $\begin{array}{l}\text { Propõem uma tipologia das tecnologias ambientais } \\
\text { e como o desenvolvimento delas influencia a } \\
\text { performance da firma }\end{array}$ & Teórico-empírica \\
\hline Kolar (2000) & $\begin{array}{l}\text { Identificou as tendências de tecnologias ambientais que } \\
\text { exploram fontes energéticas alternativas }\end{array}$ & Teórica \\
\hline Kuehr (2007) & $\begin{array}{l}\text { Verifica a pluralidade e inconsistência de definições } \\
\text { sobre tecnologias ambientais, com a proposta de uma } \\
\text { tipologia operacional }\end{array}$ & Teórica \\
\hline Lanjouw e Mody (1996) & $\begin{array}{l}\text { Verificam a geração e difusão de tecnologias ambientais } \\
\text { patenteadas }\end{array}$ & Teórico-empírica \\
\hline Layrargues (2000) & $\begin{array}{l}\text { Critica a adoção de tecnologias ambientais como } \\
\text { parâmetro absoluto de gestão ambiental empresarial }\end{array}$ & Teórica \\
\hline $\begin{array}{l}\text { Martinsons e } \\
\text { colaboradores (1997) }\end{array}$ & $\begin{array}{l}\text { Avaliam as viabilidades e requisitos para a geração de } \\
\text { tecnologias ambientais em Hong Kong e na China }\end{array}$ & Teórico-empírica \\
\hline Mazon (1992) & $\begin{array}{l}\text { Revisou a literatura sobre tecnologias ambientais e sua } \\
\text { função na prevenção da poluição }\end{array}$ & Teórica \\
\hline
\end{tabular}




\begin{tabular}{|c|c|c|}
\hline Pesquisa & Principal contribuição & Natureza \\
\hline Moore e Miller (1994) & $\begin{array}{l}\text { Avaliam o mercado para tecnologias ambientais, } \\
\text { explorando dados do Japão, Alemanha e Estados } \\
\text { Unidos da América }\end{array}$ & Teórico-empírica \\
\hline Noci e Verganti (1999) & $\begin{array}{l}\text { Analisam o desenvolvimento de tecnologias ambientais } \\
\text { em produtos e processos nas pequenas e médias } \\
\text { empresas }\end{array}$ & Teórico-empírica \\
\hline Olson (1991) & $\begin{array}{l}\text { Apresenta tendências das tecnologias ambientais e suas } \\
\text { características }\end{array}$ & Teórica \\
\hline ONU (1992) & $\begin{array}{l}\text { No capítulo } 34 \text { da Agenda 21, conceitua tecnologias } \\
\text { ambientais, esclarece seus desafios inerentes e a } \\
\text { necessidade de transferência dessas tecnologias entre } \\
\text { os países }\end{array}$ & Teórica \\
\hline Smith (2001) & $\begin{array}{l}\text { Pesquisa a geração de tecnologias ambientais em } \\
\text { pequenas e médias empresas do Reino Unido, } \\
\text { propondo uma tipologia das empresas desenvolvedoras }\end{array}$ & Teórico-empírica \\
\hline $\begin{array}{l}\text { Vachon e Klassen } \\
\text { (2007) }\end{array}$ & $\begin{array}{l}\text { Investigam a difusão de tecnologias ambientais na } \\
\text { cadeia de suprimentos }\end{array}$ & Teórico-empírica \\
\hline Weiss (2007) & $\begin{array}{l}\text { Investiga a influência de agentes e aspectos locais na } \\
\text { geração de tecnologias ambientais pela indústria de } \\
\text { papel e celulose na Alemanha }\end{array}$ & Teórico-empírica \\
\hline
\end{tabular}

À luz dos argumentos de Conway e Steward (1998) afirma-se que há um importante debate da literatura em gestão, qual seja, aquele que aborda o crescente reconhecimento de que as novas tecnologias devem ser mais "verdes" que no passado. Para os autores, no cerne desse debate está presente o argumento de que, acentuadamente, questões como ecoeficiência, emissões e reciclagem são elementos críticos do processo de geração de novas tecnologias ambientais. Entretanto, adicionalmente a essa proposta, é necessário o desenvolvimento de novos materiais (Halada, 2003), para além do enfoque proposto por tais.

Três definições sobre tecnologia ambiental despontam como mais apropriadas e completas. Na primeira delas, Kuehr (2007) afirma que as tecnologias ambientais fomentam a melhoria contínua de processos, produtos e serviços, por meio da adequada conservação de matérias-primas e energia, reduzindo o consumo de substâncias tóxicas, desperdícios de recursos naturais e geração de poluição durante o ciclo produtivo. Na segunda proposta de conceituação, Vachon e Klassen (2007) indicam que as tecnologias ambientais podem ser amplamente definidas como a adoção de técnicas de design, equipamentos e procedimentos operacionais que limitam ou reduzem os impactos ambientais 
de produtos e serviços no ambiente natural. A terceira conceituação destaca que as tecnologias ambientais podem ser compreendidas como hardwares ou softwares que se relacionam com o desenvolvimento de produtos e processos verdes, envolvendo tecnologias que reduzem o consumo de energia, previnem a poluição e reciclam os resíduos (Chen, Lai e Wen, 2006).

Assim, pode-se sistematizar o seguinte significado, ainda não cabal, para tecnologia ambiental: constitui o desenvolvimento de hardwares ou softwares, que, por meio da adoção de novos conceitos de design, equipamentos e procedimentos operacionais, passa a incorporar práticas de melhoria contínua de seu desempenho ambiental, principalmente por utilizar matérias-primas de baixo impacto ambiental, processá-las de forma eficiente e fomentar o reaproveitamento e mínimo desperdício de seus produtos finais, alterando os produtos e processos de um dado ciclo produtivo.

Grande parte da confusão terminológica e conceitual observada engendra-se por que os pesquisadores tendem a propor definições gerais para tecnologia ambiental, desconsiderando-se que tal categoria engloba, na verdade, diversos tipos, cada qual com uma definição. Assim, a próxima seção aborda as tipologias das tecnologias ambientais.

\section{Tipologia das tecnologias ambientais}

Segundo Hall e Kerr (2003), as propostas de inovações em tecnologias ambientais engendram um paradoxo complexo, cuja interpretação determina o tipo de tecnologia ambiental que será escolhida para desenvolvimento. Isso porque, se por um lado a geração de rupturas radicais nesse campo depende de um esforço inovador superior ao exigido para o desenvolvimento de abordagens incrementais, além de apresentar um risco maior para empresas desenvolvedoras e poder ser mais contestada por alguns grupos de stakeholders; por outro lado há uma crença de que, a despeito de necessária, a geração de tecnologias ambientais incrementais não é capaz de fazer frente aos atuais imperativos ambientais.

Nesse contexto, para além dos tipos radical e incremental, cabe destacar a proposta de tipologias ambientais desenvolvida por Kuehr (2007). O autor afirma que a formulação de uma tipologia das tecnologias ambientais constitui uma carência da literatura especializada. Assim, ele empreendeu uma tipologia oriunda, principalmente, de sua percepção e experiência sobre o tema. Sua proposta é de que o conjunto das tecnologias ambientais pode ser dividido em quatro categorias (figura 1), a saber: 
v tecnologia de mensuração ambiental — envolve ferramentas, instrumentos, equipamentos e sistemas de gestão da informação para mensuração e controle ambientais. Uma categoria desse tipo possui como objetivo fornecer uma gama confiável de opções para a tomada de decisões sobre a qualidade do meio ambiente; outra categoria objetiva fornecer à humanidade informações úteis na busca por alternativas ambientais, como, por exemplo, a falta de água e aquecimento global. A tecnologia de mensuração ambiental contrasta com suas congêneres por não focar necessariamente na redução dos impactos produzidos pela humanidade sobre o ambiente natural, mas sim por subsidiar o entendimento de como o meio ambiente vem se alterando e quais são as melhores alternativas para minimizar os impactos dessas alterações sobre a perspectiva de qualidade de vida da população;

- tecnologias de controle da poluição - engloba o conjunto de processos e materiais que foram desenvolvidos para neutralizar os impactos gerados durante o ciclo produtivo, sem, necessariamente, implicar modificações nos processos originais. Em outras palavras, tais tecnologias apoiam o controle da poluição gerada em um determinado processo, sem alterá-lo completamente. Se por um lado tais tecnologias podem controlar a poluição; por outro podem gerar outros tipos de impactos ambientais, como, por exemplo, aumento no consumo de energias;

- tecnologias mais limpas ou de prevenção da poluição — diz respeito às modificações empreendidas para minimizar ou até mesmo eliminar qualquer efeito prejudicial que um processo pode gerar no meio ambiente. Diferemse das tecnologias de controle da poluição por requererem uma perspectiva holística de como podem ser reduzidos os impactos ambientais de um processo ou produto;

- tecnologias ambientais de impacto nulo - tecnologias que, de fato, não geram impacto algum durante seu processo de desenvolvimento e utilização. Dentro de uma perspectiva pontual, essas tecnologias podem ser observadas no campo da biotecnologia, mas no contexto de um ciclo produtivo completo, sua existência é considerada utópica.

Como se percebe, a tipologia das tecnologias ambientais defendida por Kuehr (2007) possui similaridades com as abordagens de outras pesquisas, mas o autor avança nesse sentido ao refletir sobre os dois tipos de tecnologias que ocupam os extremos dessa proposta: as tecnologias de mensuração ambiental e de impacto nulo.

Em outra proposta tipológica das tecnologias ambientais, Klassen e Whybark (1999) indicam a existência de três categorias: prevenção da po- 
luição; controle da poluição; sistemas de gestão. A despeito das duas primeiras categorias terem sido abordadas por Kuerh (2007), esses autores adicionam o sistema de gestão ambiental como tecnologia organizacional e o conceituam como investimentos que melhoram a forma com que as questões ambientais são incorporadas na manufatura e na gestão organizacional como um todo. Assim, adiciona-se à perspectiva de Kuehr (2007) uma quinta categoria de tecnologias ambientais: o sistema de gestão ambiental, certificado ou não.

\section{Figura 1}

\section{A tipologia das tecnologias ambientais}

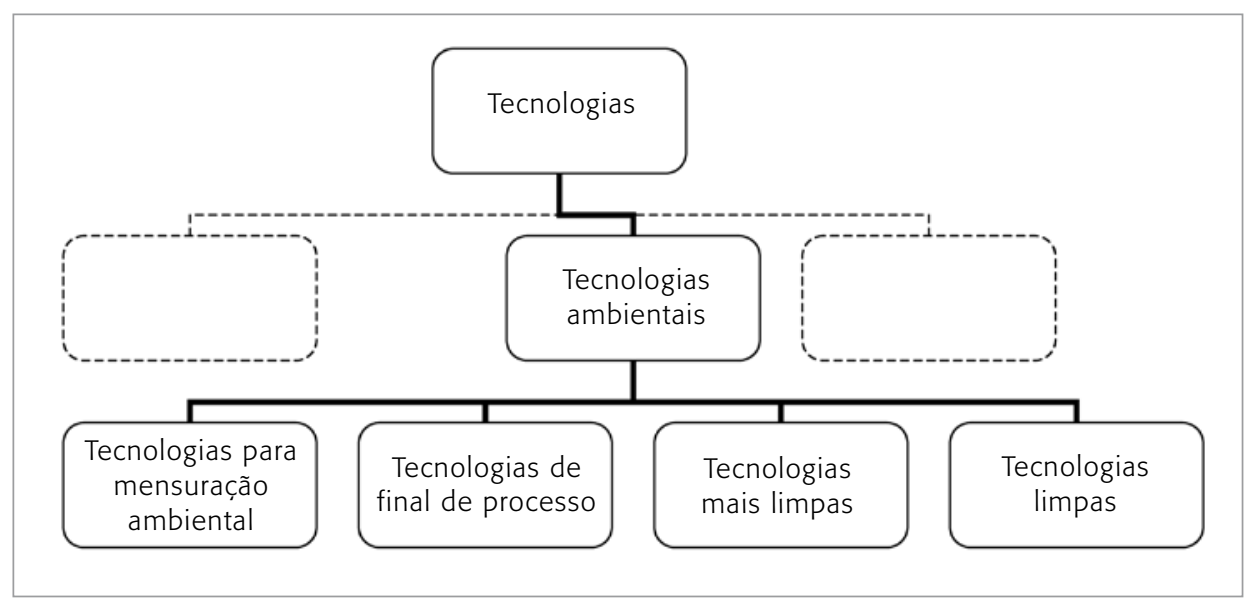

Fonte: Adaptado de Kuehr (2007:4).

Aceitar a existência de uma tipologia das tecnologias ambientais implica aceitar como válida a existência de uma tipologia de empresas desenvolvedoras de tecnologias ambientais. Nesse contexto, torna-se especialmente relevante a proposta de Smith (2001), autora que classifica as empresas desenvolvedoras de tecnologias ambientais em três tipos (quadro 2).

Como corolário, cabe a reflexão de que as tecnologias de controle e prevenção da poluição, indicadas por Kuehr (2007), tendem a ser desenvolvidas pelas chamadas empresas ambientalmente intermediárias (Smith, 2001), e as tecnologias de impacto nulo tendem a ser desenvolvidas pelas empresas ambientalmente intensivas (Smith, 2001). Por fim, cabe ressaltar que tanto as tecnologias de mensuração ambiental (Kuehr, 2007), quanto os sistemas de gestão ambiental (Klassen e Whybark, 1999) tendem a ser desenvolvidos nas empresas fornecedoras de serviços ambientais (Smith, 2001). Esse último 
grupo tende a englobar empresas desenvolvedoras de softwares para a análise do ciclo de vida de produtos e design for environment, além das empresas de consultoria ambiental.

Quadro 2

Tipologia das empresas desenvolvedoras de tecnologias ambientais

\begin{tabular}{|c|c|c|}
\hline Tipo & Características & Nichos explorados \\
\hline $\begin{array}{l}\text { Empresa } \\
\text { ambientalmente } \\
\text { "intermediária" }\end{array}$ & $\begin{array}{l}\text { Geralmente são empresas baseadas em } \\
\text { engenharia que alteraram seus produtos } \\
\text { convencionais para produtos ambientalmente } \\
\text { melhorados, em termos de performance ou } \\
\text { benefícios. Grande enfoque em soluções } \\
\text { ambientais, incluindo redução de desperdícios }\end{array}$ & $\begin{array}{l}\text { Produtos ativados por energia } \\
\text { solar, conversores de energia } \\
\text { solar, materiais alternativos } \\
\text { para embalagens, baterias } \\
\text { recarregáveis e produtos } \\
\text { similares }\end{array}$ \\
\hline $\begin{array}{l}\text { Empresa } \\
\text { ambientalmente } \\
\text { "intensiva" }\end{array}$ & $\begin{array}{l}\text { Empresas com uma visão sistêmica da } \\
\text { inserção da dimensão ambiental no contexto } \\
\text { de seus negócios, cuja atuação é inerente ao } \\
\text { desenvolvimento de tecnologias ambientais }\end{array}$ & $\begin{array}{l}\text { Produtos para tratamento de } \\
\text { efluentes, tecnologias alternativas } \\
\text { radicais }\end{array}$ \\
\hline $\begin{array}{l}\text { Empresa } \\
\text { de serviços } \\
\text { "ambientais" }\end{array}$ & $\begin{array}{l}\text { Empresas não manufatureiras e gerenciadoras } \\
\text { de informaç̃̃es. Utilizam e entregam serviços } \\
\text { que objetivam a redução de impactos } \\
\text { ambientais }\end{array}$ & $\begin{array}{l}\text { Produtoras de vídeos para } \\
\text { treinamento ambiental, } \\
\text { instituições financeiras } \\
\text { ambientalmente orientadas, } \\
\text { softwares para a análise do ciclo } \\
\text { de vida dos produtos }\end{array}$ \\
\hline
\end{tabular}

Fonte: Baseado em Smith (2001:23).

Dessa forma, é possível avançar na busca por um significado do conceito de tecnologia ambiental, complementando a definição apresentada na seção 2 com a seguinte conceituação: tais tecnologias podem ser classificadas em tecnologias de controle e prevenção da poluição, tecnologias de mensuração e organizacionais; além das tecnologias de impacto ambiental nulo. Tais categorias tendem a se desenvolver, respectivamente, em empresas ambientalmente intermediárias, empresas de serviços ambientais e empresas ambientalmente intensivas.

\section{Mecanismos de desenvolvimento e difusão}

O desenvolvimento de tecnologias ambientais é, geralmente, um processo mais complexo do que o desenvolvimento de outros tipos tecnológicos. Segundo Hall e Vrendenburg (2003), atribui-se complexidade adicional a esse processo pois: 
- a geração de inovações ambientalmente adequadas demanda, em muitos casos, contradizer o senso comum e a perspectiva da racionalidade econômica, que postula que as ações empresariais devem objetivar incremento no lucro, exclusivamente;

v gerar tecnologias ambientais requer a aceitação da "voz" dos stakeholders, que devem emitir opiniões para o processo de geração de inovações.

A primeira dificuldade imposta ao desenvolvimento de tecnologias ambientais, segundo Hall e Vrendenburg (2003), é a crença de que, dificilmente, a adoção de tecnologias ambientais por parte das firmas implicará geração de lucros para as mesmas. Entretanto, essa afirmação pode ser contestada, uma vez que, conforme Kuehr (2007), estima-se que o mercado das tecnologias ambientais movimente, no contexto mundial, cerca de $€ 478$ bilhões/ano, o que levou a tecnologia ambiental a ser considerada um green gold (Moore e Miller, 1994). Não obstante, há evidências de que a adoção de tecnologias ambientais pelas firmas coincide com incremento na competitividade destas (Chen, Lai e Wen, 2006).

O segundo desafio para o desenvolvimento de tecnologias ambientais a que se referem Hall e Vrendenburg (2003) pode ser facilitado com uma perspectiva holística que mapeie os agentes interessados e afetados por uma nova tecnologia ambiental. Três grupos de agentes-chave para o processo de geração de tecnologias ambientais foram identificados por Conway e Steward (1998), os quais devem ser incluídos nesse processo, para a garantia da negociação com os stakeholders:

v criadores de conhecimentos, agentes de transferência e consultores - envolve agentes que criam o conhecimento essencial das tecnologias ambientais, tais como institutos de pesquisa e desenvolvimento e universidades, e aqueles que auxiliam no processo de transferência dessa tecnologia, tais como consultores e escritórios de transferência de tecnologia;

v criadores e usuários - envolve os criadores da tecnologia ambiental, que podem fornecê-la para o consumidor final ou para outras firmas, no caso de empresas de bens de capital. Cabe ressaltar que esses criadores podem gerar a tecnologia ambiental independentemente ou por meio de transferência de tecnologia do grupo anterior;

- representações e poder público - envolve, geralmente, grupos de pressão, normalização e incentivos à geração de tecnologias ambientais, tais como o estímulo governamental para o desenvolvimento de tecnologias ambientais. 
Para além da tecnologia ambiental desenvolvida, cabe uma reflexão desafiadora sobre sua difusão. A difusão de tecnologias ambientais e sua transferência, dentro das fronteiras de um país, principalmente no sentido centro-periferia, são fatores apontados como necessários para qualquer proposta de desenvolvimento sustentável (ONU, 1992). Segundo a ONU (1992), no campo da transferência das tecnologias ambientais, faz-se mister o esforço colaborativo entre os componentes do sistema de inovação de uma dada nação, e entre as nações, principalmente no que tange à transferência de tecnologias ambientais dos países centrais para os países periféricos, cujo vigoroso crescimento econômico tende a acompanhar a geração de grandes impactos ambientais. Tal perspectiva colaborativa "supõe esforços comuns das empresas e dos governos, ambos provedores e receptores de tecnologia". Entretanto, o estabelecimento desse ciclo de apoio "exige necessariamente treinamento sistemático e continuado" (ONU, 1992) e, a despeito de relevante, ainda pouco se sabe de como ocorre a disseminação de tecnologias ambientais no contexto de um país e internacionalmente (Lanjouw e Mody, 1996).

No contexto nacional da difusão de tecnologias ambientais, assume importância o argumento de que o governo desempenha um papel fundamental nos seguintes aspectos: geração de regulamentações ambientais que fomentam a adoção dessas tecnologias pelas firmas; fornecimento de suporte econômico para a adoção dessas tecnologias pelas firmas; utilização do poder de compra público para privilegiar a aquisição de tecnologias limpas, contribuindo para o ganho em escala dessa produção (Hall e Clark, 2003).

Segundo Kivimaa e Mickwitz (2006), o fomento governamental para o desenvolvimento e difusão das tecnologias ambientais pode ser viável por meio do uso da ciência e tecnologia para se atingir objetivos ambientais, o que se dá por meio da inserção da dimensão ambiental na política científica e tecnológica de um país. Essa inserção requer, necessariamente, dois tipos de integração. No primeiro deles, ocorre a integração vertical, em que a dimensão ambiental passa a ser discutida nos diversos níveis dos entes governamentais; no segundo ocorre a integração horizontal, no conjunto de ações de cada uma dessas esferas (figura 2). Nesse sentido, Lafferty e Hovden (2003) sugerem que a inserção da dimensão ambiental na política de ciência e tecnologia governamental pode ser sensivelmente melhorada se:

v inserir a dimensão ambiental nas diversas esferas de decisões sobre fomento tecnológico, com a criação de esferas para a discussão do fomento ao desenvolvimento de tecnologias ambientais em específico; 
- reduzir as contradições setoriais e entre as diversas esferas governamentais para o desenvolvimento de tecnologias ambientais, posicionando-o como prioridade.

Extrapolando a perspectiva da difusão nacional, Martinsons e colaboradores (1997) ressaltam a importância da transferência de tecnologias ambientais dos países centrais para os periféricos. Por exemplo, esse processo é relevante para a redução dos grandes impactos ambientais que o acelerado crescimento econômico chinês vem suscitando. Para esses pesquisadores, o desenvolvimento de tecnologias ambientais requerido por alguns países asiáticos, em especial a China, será viável à medida que os conhecimentos pertinentes a esse tipo tecnológico puderem ser transferidos de países que já o detêm, ou desenvolvido nos países periféricos, com transferência de expertise e estabelecimento de acordos de cooperação entre centros de pesquisa e tecnologia internacionais. Além disso, demandará um esforço governamental para a inserção de aspectos ambientais no sistema de ciência e tecnologia do país, como vem ocorrendo na China (Liu, Cai e Ying, 2005).

Lanjouw e Mody (1996) esclarecem que essa transferência desdobrase incorporada aos produtos, ou é realizada por meio de difusão de conhecimentos técnicos e licenciamento de patentes. Dois fluxos de transferência se estabelecem: de conhecimentos e de bens. No campo da transferência de conhecimentos, pode-se citar o esforço do governo chinês para a cooperação multilateral e formulação de convênios entre centros de pesquisa e desenvolvimento para a formação de recursos humanos para o desenvolvimento de tecnologias ambientais, o que é um desafio para esses centros de formação.

No campo da difusão de tecnologias incorporadas aos bens, cabe a transposição de duas barreiras identificadas por Hall e Clark (2003). A primeira delas pode ser conceituada como o desafio do balanceamento das tecnologias ambientais difundidas, que diz respeito à difusão das tecnologias ambientais por várias indústrias afins, dentro de uma mesma cadeia produtiva. Assim, pode-se exemplificar que a adoção de tecnologias ambientais pela indústria automobilística depende do desenvolvimento de tecnologias ambientais pela indústria de energia e de componentes automotivos. A outra barreira observada para a difusão física das tecnologias ambientais concerne aos desafios inerentes ao processo de transbordamento da tecnologia ambiental desenvolvida em centros de pesquisa e desenvolvimento para o setor industrial, o que se vincula à viabilidade de aplicação dos conhecimentos disponíveis sobre tecnologias ambientais. 
Figura 2

O papel da política de ciência e tecnologia no desenvolvimento de tecnologias ambientais

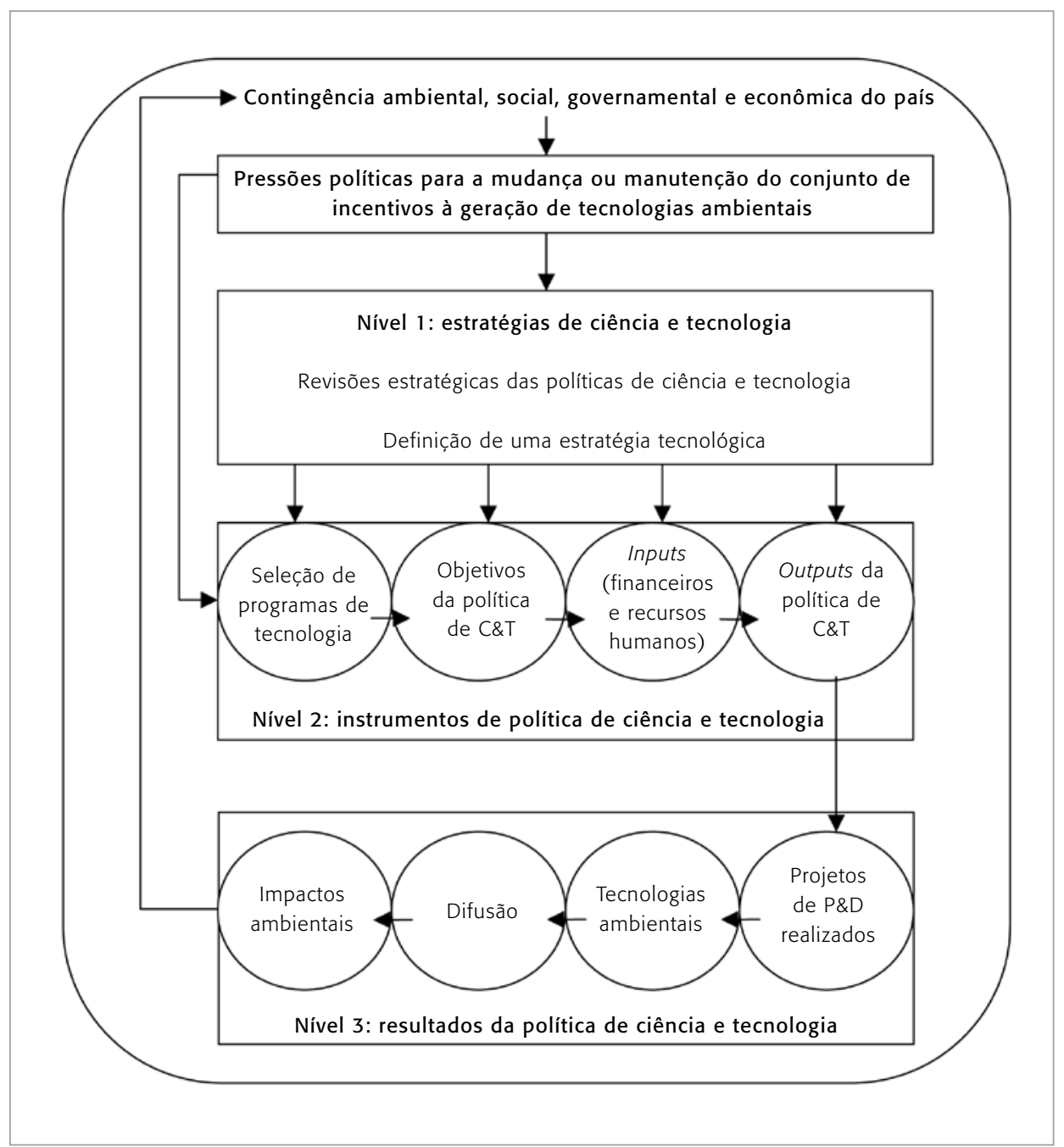

Fonte: Adaptado de Kivimaa e Mickwitz (2006:733).

Com base nas reflexões desta seção, na busca por um significado de tecnologia ambiental, torna-se imperativo considerar que seu desenvolvimento requer fomento governamental, por meio de sua incorporação nas políticas de ciência e tecnologia, formação de recursos humanos, estrutura para pesquisa e 
articulação de redes de cooperação. No contexto nacional, tendem a se difundir dos centros de pesquisa e desenvolvimento para as empresas, que podem obter vantagens financeiras advindas de sua adoção. Já no contexto internacional, difundem-se por meio de transferência de conhecimentos ainda não aplicados ou já incorporados em produtos e exportados pelas empresas desenvolvedoras, devendo-se incentivar o fluxo difusor de tecnologias ambientais desenvolvidas em países centrais para as nações periféricas.

\section{Considerações finais}

No contexto das tecnologias ambientais, emerge da literatura uma pluralidade terminológica, seguida de propostas conceituais que tendem a não fornecer um significado preciso. Essa confusão conceitual tende a entravar o entendimento comum do que é uma tecnologia ambiental. Entretanto, como se discorreu aqui, o entendimento comum do significado é imprescindível para que a tecnologia ambiental seja gerada e, mais ainda, para que ela seja difundida. Como se pode afirmar a imprescindibilidade do desenvolvimento e adoção de tecnologias ambientais entre atores, redes organizacionais, firmas e nações quando a literatura especializada carece de significado mais completo sobre tal conceito?

Assim, ao buscar-se um significado de tecnologia ambiental, este artigo propõe o desenvolvimento de hardwares ou softwares que, por meio da adoção de novos conceitos de design, equipamentos e procedimentos operacionais, passam a incorporar práticas de melhoria contínua de desempenho ambiental, principalmente por utilizar matérias-primas de baixo impacto ambiental, processá-las de forma eficiente, fomentar o reaproveitamento e o mínimo desperdício de seus produtos finais, alterando um dado ciclo produtivo. Tais tecnologias podem ser classificadas em: tecnologias de controle e prevenção da poluição; tecnologias de mensuração e organizacionais; além das tecnologias de impacto ambiental nulo. Tais categorias tendem a se desenvolver, respectivamente, em empresas ambientalmente intermediárias, empresas de serviços ambientais e empresas ambientalmente intensivas. Esse desenvolvimento requer fomento governamental, por meio de sua incorporação nas políticas de ciência e tecnologia, formação de recursos humanos, estrutura disponível para pesquisa e articulação de redes de cooperação. No contexto nacional, tendem a se difundir dos centros de pesquisa e desenvolvimento para as empresas, que podem obter vantagens financeiras advindas de sua adoção. Já no contexto internacional, difundem-se por meio de transferência de conhecimentos ainda 
não aplicados ou já incorporados a produtos, devendo-se incentivar o fluxo difusor no sentido centro-periferia.

Como afirmam Hall e Clark (2003), superados os desafios da conceituação, desenvolvimento e difusão de tecnologias ambientais, o próximo estágio é abordar o paradigma das tecnologias sustentáveis, que extrapolam o significado de tecnologia ambiental. Tendo em vista as complexas implicações conceituais, associadas ao termo tecnologia sustentável, será requerida uma nova busca conceitual.

\section{Referências}

AZZONE, G.; BERTELÈ, U.; NOCI, G. At last we are creating environmental strategies which work. Long Range Planning, v. 30, n. 4, p. 562-571, 1997.

BARBIERI, J. C. Políticas públicas indutoras de inovações tecnológicas ambientalmente saudáveis nas empresas. Revista Brasileira de Administração Pública, v. 31, n. 2, p. 135-152, 1997.

. Gestão ambiental empresarial: conceitos, modelos e instrumentos. São Paulo: Saraiva, 2004.

BRÍO, J. A.; JUNQUERA, B. A review of the literature on environmental innovation management in SMEs: implications for public policies. Technovation, v. 23, p. 939-948, 2003.

CHEN, Y.; LAI, S.; WEN, C. The influence of green innovation performance on corporate advantage in Taiwan. Journal of Business Ethics, v. 67, p. 331-339, 2006.

CONWAY, S.; STEWARD, F. Networks and interfaces in environmental innovation: a comparative study in the UK and Germany. The Journal of High Technology Management Research, v. 9, n. 2, p. 239-253, 1998.

CUNHA-E-SÁ, M. A.; REIS, A. B. The optimal timing of adoption of a green technology. Environmental \& Resource Economics, v. 36, p. 35-55, 2007.

DONAIRE, D. Gestão ambiental na empresa. São Paulo: Atlas, 1999.

GREEN, K.; McMEEKIN, A.; IRWIN, A. Technological trajectories and R\&D for environmental innovation in UK firms. Futures, v. 26, n. 10, p. 1047-1059, 1994.

HALADA, K. Progress of ecomaterials toward a sustainable society. Current Opinion in Solid State and Materials Science, v. 7, n. 3, p. 209-216, 2003.

HALL, J.; VRENDENBURG, $\mathrm{H}$. The challenges of innovating for sustainable development. MIT Sloan Management Review, v. 45, n. 1, p. 61-68, 2003. 
; CLARK, W. Environmental innovation. Journal of Cleaner Production, v. 11, p. 343-346, 2003.

; KERR, R. Innovation dynamics and environmental technologies: the emergence of fuel cell technology. Journal of Cleaner Production, v. 11, n. 4, p. 459-471, 2003.

JAFFE, A. B.; NEWELL, R. G.; STAVINS, R. N. A tale of two market failures: technology and environmental policy. Ecological Economics, v. 54, p. 164-174, 2005.

KERR, R.; HALL, J. Innovation dynamics and environmental technologies: the emergence of fuel cell technology. Journal of Cleaner Production, v. 11, p. 459471, 2003.

KIVIMAA, P.; MICKWITZ, P. The challenge of greening technologies: environmental policy integration in finnish technology policies. Research Policy, v. 35, p. 729-744, 2006.

KLASSEN, R. D.; WHYBARK, D. C. The impact of environmental technologies on manufacturing performance. Academy of Management Journal, v. 42, n. 6, p. 599615, 1999.

KOLAR, J. L. Alternative energy technologies. Environmental Quality Management Journal, p. 45-53, 2000.

KUEHR, R. Environmental technologies: from a misleading interpretations to an operational categorization and definition. Journal of Cleaner Production, 2007.

LAFFERTY, W. M.; HOVDEN, E. Environmental policy integration: towards an analytical framework. Environmental Politics, v. 12, n. 3, p. 1-22, 2003.

LANJOUW, J. O.; MODY, A. Innovation and the international diffusion of environmentally responsive technology. Research Policy, v. 25, p. 549-571, 1996.

LAYRARGUES, P. P. Sistemas de gerenciamento ambiental, tecnologia limpa e consumidor verde: a delicada relação empresa-meio ambiente no eco-capitalismo. Revista de Administração de Empresas, v. 40, n. 2, p. 80-88, 2000.

LIU, Y.; CAI, L.; YING, W. Chinese environmental education and technology development programs. Environmental Progress, v. 24, n. 3, p. 250-254, 2005.

MARTINSONS, M. G. et al. Hong Kong and China: emerging markets for environmental products and technologies. Long Range Planning, v. 30, n. 2, p. 277-290, 1997.

MAZON, R. Em direção a um novo paradigma de gestão ambiental: tecnologias limpas ou prevenção da poluição. Revista de Administração de Empresas, v. 32, n. 2, p. 78-98, 1992. 
MOORE, C.; MILLER, A. Green gold. Boston: Beacon Press, 1994.

NOCI, G.; VERGANTI, R. Managing green product innovation in small firms. $R \& D$ Management, v. 29, n. 1, p. 3-14, 1999.

OLSON, R. L. The greening of high tech. The Futurist, v. 25, n. 3, p. 28-34, 1991.

ORGANIZAÇÃO DAS NAÇÕES UNIDAS (ONU). Agenda 21. Rio de Janeiro: CMMED, 1992.

ROUNDS, K. S.; COOPER, J. S. Development of product design requirements using taxonomies of environmental issues. Research in Engineering Design, v. 13, p. 94-108, 2002.

SMITH, M. T. Eco-innovation and market transformation. The Journal of Sustainable Product Design, v. 1, p. 19-26, 2001.

UNEP. Environmentally sound technologies in wastewater treatment for the implementation of the Unep Global Programme of Action (GPA) "Guidance on Municipal Wastewater". Japan, 2002.

VACHON, S.; KLASSEN, R. D. Supply chain management and environmental technologies: the role of integration. International Journal of Production Research, 2007.

VANDERMERWE, S.; OLIFF, S. Customers drive corporations green. Long Range Planning, v. 23, n. 6, p. 10-16, 1990.

WEISS, G. The influence of the local level on innovations in environmental technology: the case of the German kraft pulp industry. Geoforum, 2007. 